\title{
Biomedical Perspectives about Women with Chronic Pelvic Pain: A Qualitative Analysis
}

\author{
Paula P. Souza ${ }^{1}$, Adriana P. M. S. Romão ${ }^{1}$, Ana Márcia S. Nakano², Julio C. Rosa-e-Silva ${ }^{3}$, \\ Francisco J. Candido-dos-Reis ${ }^{3}$, Antonio A. Nogueira ${ }^{3}$, Omero B. Poli-Neto ${ }^{3 *}$ \\ ${ }^{1}$ Department of Gynaecology and Obstetrics, School of Medicine University Hospital, University of São Paulo at Ribeirão Preto, \\ Ribeirão Preto, Brazil; ${ }^{2}$ Department of Public Health, School of Nursing, University of São Paulo at Ribeirão Preto, Ribeirão Preto, \\ Brazil; ${ }^{3}$ School of Medicine University Hospital, University of São Paulo at Ribeirão Preto, Ribeirão Preto, Brazil. \\ Email: paulaps@usp.br, adrianapeterson@usp.br, nakano@eerp.usp.br, juliocrs@convex.com.br, fjcreis@fmrp.usp.br, \\ aanoguei@fmrp.usp.br, ${ }^{*}$ polineto@fmrp.usp.br
}

Received June $18^{\text {th }}, 2012$; revised July $19^{\text {th }}, 2012$; accepted July $28^{\text {th }}, 2012$

\begin{abstract}
Because the aetiology of chronic pelvic pain is complex, studies of the condition involve extensive investigation but provide few conclusions. Numerous studies have addressed the experiences of women with chronic pelvic pain, as well as the interaction between those women and their health care providers. Our objective was to investigate how physicians at a specialized clinic perceive the medical care provided to such women. This was a qualitative study employing semi-structured interviews and content analysis. We interviewed seven physicians at the Chronic Pelvic Pain Outpatient Clinic of the University Hospital, Faculty of Medicine of Ribeirão Preto, University of São Paulo, Brazil. Medical training and practice constituted the central theme of the study, which was subdivided into categories addressing the influence that the current medical training has on the type of medical care provided to women with chronic pelvic pain. Medical practice has been characterized by a reductionist approach to health and illness, as well as by the fragmentation of health care. These characteristics are, to a certain extent, the result of the biomedical model of education, which has been predominant, ignoring social, cultural, psychological and emotional aspects. There is a need to shift the medical paradigms toward a humanistic model of health care. We hope that we have provided a critical view of current medical training and practice, as well as of their effects in various health care settings, particularly in the provision of care to women with chronic pelvic pain.
\end{abstract}

Keywords: Chronic Pelvic Pain; Biomedical Model; Qualitative Research

\section{Introduction}

Since the days of the earliest civilizations, pain has caused intense suffering among individuals [1]. In the past, the understanding of pain was strongly influenced by Christianity, which defined pain as a means of achieving enlightenment or obtaining blessings; therefore, studies investigating the elimination of pain were discouraged, which, to a certain extent, delayed the investigation of the pathophysiology of pain [2]. In mid-1979, the International Association for the Study of Pain proposed the first definition that included sensory and emotional aspects, as well as being subjective in nature and varying among individuals: pain is an unpleasant sensory and emotional experience associated with actual or potential tissue damage, or described in terms of such damage [3]. In recent decades, the abovementioned measures have contributed to a better understanding of

${ }^{*}$ Corresponding author. pain. However, because pain—unlike the remaining vital signs - is subjective, there is no standard instrument that allows an outside observer to measure pain in an objective manner, precisely because pain is an extremely complex and individual experience. Therefore, in order to gain a deeper understanding of pain, it is necessary to consider the clinical correlates of pain, as well as the emotional, cognitive, and personality characteristics of individuals $[4,5]$.

This context allows us to reflect on the issue of women with chronic pelvic pain (CPP), which is a disease of complex aetiology resulting from the interaction among the gastrointestinal, genitourinary, musculoskeletal, nervous, psychological, and endocrine systems, as well as being influenced by socio-cultural factors [6]. Studies of CPP typically involve extensive investigation but provide few conclusions; this failure to understand chronic pelvic pain leads to dissatisfaction and frustration among patients and health professionals alike, as well as to con- 
flicts between the parties involved. One of the elements of this complexity is the very definition of the condition, for which there is no consensus [7]. Although there are various definitions of CPP, most, if not all, tend to state that the aetiology of the condition is exclusively physical or behavioural and are therefore inadequate. In our opinion, the most appropriate definition of CPP in women is as follows: "noncyclic pain of 6 or more months' duration that localizes to the anatomic pelvis, anterior abdominal wall at or below the umbilicus, the lumbosacral back, or the buttocks and is of sufficient severity to cause functional disability or lead to medical care" [8].

The overall prevalence of CPP in women has been estimated at $3.8 \%$, being similar to that of migraine, asthma, and back pain [9,7]. The prevalence of CPP has been estimated to be higher in developing countries [10]. For example, its prevalence in Brazil is approximately $11 \%$ [11]. The direct and indirect costs of CPP (including medical costs, as well as costs related to laboratory tests and reduced productivity) have been estimated at 39 billion dollars per year [12-14]. In addition, CPP accounts for approximately $10 \%$ of all gynaecological appointments, $40 \%-50 \%$ of all gynaecological laparoscopies [15], and $12 \%$ of all hysterectomies [16-18].

Approximately 20\% of all women with CPP do not undergo any diagnostic investigation, and $60 \%$ do not receive a specific diagnosis [19]. In addition, Silva et al. [11] found that although $90 \%$ of all women with CPP were being routinely followed at primary health care clinics and had previously complained of their clinical status, only a small proportion (4\%) were aware of having the disease. The above mentioned findings show some of the reasons why women with CPP are highly dissatisfied [20]. The resolution rates for CPP are low. This might be at least partially attributable to the fact that there is a disconnect between the expectations of women with such pain and the type of medical care provided, which does not meet their needs. We believe that the difficulty health professionals have in managing the condition is intrinsically related to the policies and philosophical underpinnings that guide current medical education and practice, which are based on scientific medicine, the form of medicine derived from the Flexnerian reform of medical education in the early 20th century [21].

Abraham Flexner was responsible for the most important reform of the medical schools in the United States, his report-informally known as the Flexner Reporthaving had a major impact on medical education in numerous countries, including Brazil. The Flexner report proposed a new model of medical education and practice, based on biological evidence, individualism, specialisation, and a technical approach to health, as well as on the curative.

The impact of the Flexnerian model on the medical care provided to women with CPP is not entirely positive, as evidenced by the complaints of such women. Most of the complaints are related to the lack of a holistic approach to the problem, biological aspects being prioritised. The most common complaints are dissatisfaction with the doctor-patient relationship, the lack of an underlying etiology for CPP, miscommunication between doctors and patients, the lack of information regarding the condition, and inappropriate treatment. CPP imposes limitations to the lives of those women and is responsible for years of suffering, including job loss and divorce. When women with CPP seek professional help, they have an overwhelming desire to know what is wrong with their bodies [22]. In contrast, it seems that the biomedical model of medical education does not equip medical students with the skills required in order to manage the psychosocial aspects of CPP and its various dimensions.

The quality of that relationship is one of the factors that determine the level of patient satisfaction, having a direct influence on patient response to treatment $[23,24]$. Patients who report dissatisfaction with their encounters with physicians are more likely to show psychiatric disorders, aggressive personality traits $[25,26]$, and lower adherence to treatment $[27,28]$, as well as to report multiple physical symptoms that cannot be explained biologically (i.e., "medically") $[25,29,30]$. By context, the principal objectives of the present study were to investigate physician perception of the medical care provided to women with CPP and identify possible determinants of the condition for future development of continuing education programmes.

\section{Methods}

This was a qualitative study, data were collected by means of semi-structured interviews. We interviewed seven physicians providing medical care to women with CPP treated at the CPP Outpatient Clinic of the University Hospital, Faculty of Medicine of Ribeirão Preto, University of São Paulo, Brazil. The median age of the physicians was 30 years (range, 27 - 58 years). Among the seven doctors interviewed, four were men and three women. The interviews were conducted by one interviewer, with an average of 60 minutes for each participant. The analyzes were performed by three evaluators in the portuguese language and after the material was translated into English.

The criterion used to conduct the interviews and to determine the number of participants was the saturation criterion in which the repetition of information during interviews limits the need to new participants. Regarding the level of training, the participants ranged from firstyear residents to professors, and the length of experience in providing medical care to women with chronic pelvic 
pain ranged from 1 year to 10 years. Neither the length of experience nor the level of training of the participants had any impact on the results obtained, meaning that there were no significant differences among the answers provided by the participants. Therefore, there was no need for new thematic categories. All of the participants gave written informed consent, and the study was conducted in accordance with the regulations and guidelines for research involving human beings established by Brazilian National Health Council Resolution 196/96.

We performed content analysis in accordance with the method proposed by Bardin (1997) [31]. According to Minayo [32], qualitative data analysis involves a set of operations and reflections, as well as data reorganization, all of which are carried out in order to determine the significance of the phenomenon under study [32]. Data analysis was performed in three steps: Pre-analysis; Exploration of the material; Analysis and interpretation of the results.

\section{Results}

Through means of detailed discourse analysis, we attempted to understand the range of experiences of those physicians (i.e., from medical training to clinical practice). The central theme was medical training and practice, and we subdivided it into five categories, which are described below.

\subsection{Physician Knowledge of Chronic Pelvic Pain}

Physician 1: "I felt the need to know a little bit more about those diseases, about that group of patients, because I had a lot of difficulty in dealing with them."

Physician 5: "Instruction regarding chronic pelvic pain is much more theoretical than practical, isn't it? You learn what can cause the pain, but that doesn't always correlate with what the patient is telling you. Patients don't always say, 'oh, the pain I feel is like this and that', and then you can think of a course of action. It's generally not 'by the book'."

The discourse of those health professionals shows their difficulty with CPP. Physician 1 reported having difficulty in reconciling theory and practice in the context of treating patients with chronic pelvic pain. We believe that this is due to the subjective nature of the pain, which stands in contrast with the need that those physicians have to conceptualise the disease in physical terms. This indicates that greater weight is given to the biological aspects (i.e., the "concrete" aspects) of pain, an approach that is in accordance with the Flexneriano model of medical education and practice.

According to Lima \& Trad [33] the subjectivity of pain makes it invisible and unquantifiable, which is why health professionals have difficulty in managing it. Al- though the management of chronic pain has posed a major challenge for health professionals, chronic pain has not been given weight in the curricula of medical schools, being strongly associated with the ideas of injury and protection (i.e., a symptom that reveals an underlying condition to be investigated and diagnosed) [34].

Physician 3: "I think that CPP is not well taught to undergraduate students, who spend very little time within each specialty. In medical schools today, there is a trend toward a more general approach to medical education rather than a focus on specialization, on specialties."

The physician in question believes that the difficulty in managing CPP is due to the fact that undergraduate students spend very little time within each specialty. The great importance given to specialization has a direct impact on the medical care provided, which becomes fragmented; a patient is seen as parts rather than as a whole.

Although a disease is a biological, material phenomenon, the human response to the disease cannot be measured objectively. It is evident that the curricula of medical schools have not equipped students with the skills required in order to treat individuals humanistic. The fragmentation of health care into specialties tends to obscure physician perception of biopsychosocial aspects, meaning that such aspects are ultimately overlooked by physicians, who fail to correlate them with patient health status.

\subsection{Stereotypical Views That Health Professionals Hold of Chronic Pelvic Pain and of Women with the Disease}

Physician 6: "Well, you know, it's too early to tell, I haven't been to the outpatient clinic that often, and, I think it's a problem that is difficult to treat, the patients are difficult, so, I suppose I still have a lot to learn about $C P P$, and, well, I haven't studied it, I mean, I haven't done any research on my own, but we do have the outpatient clinics, where we can follow patients closely, and, anyway, I don't think we learn that much about the subject at university."

Physician 1: "It's difficult, isn't it? Doctors always want to solve everything, and all of those things that sometimes you just can't find the cause of... you see, in the case of CPP, you can't always find a cause that is treatable, sometimes you even think you've found something, but you can't solve the patient's problem, which sort of causes some frustration, you know, this is why I don't like it very much."

Some of the health professionals interviewed in the present study emphatically stated their distaste for providing medical care to women with CPP. This is probably a reflection of their inexperience with and lack of knowledge of the condition. That viewpoint has become a consensus among health professionals in training and 
specialists. The setting of treating CPP has become stigmatised, health professionals having disseminated a negative view of the disease. According to Salmon [35], the uncertainty regarding the aetiology and treatment of CPP is what concerns health professionals the most, given that it can threaten the authority on which medical knowledge and practice are based [35]. Ponte \& Johnson-Tribino36 showed that $85 \%$ of health professionals reported frustration when treating patients with chronic pain, a finding that is in agreement with those of the present study [36].

The lack of training of health professionals in managing chronic pelvic pain has had an impact not only on how the disease is viewed (i.e., negatively) but also on how women with the disease are stereotypically viewed, i.e., as having multiple complaints, as being annoying, and as being problematic.

Physician 7: "Now, it is a difficult type of patient, isn't it? We see it quite often. That's exactly why you're conducting this study, because residents, those who are younger and inexperienced, they say, 'listen, there's no way you can treat that patient, she complains of everything, she has multiple complaints, there's just no way, there's no treating her, everything hurts (laughs), nothing works, nothing heals, and everything hurts'."

Physician 1: "The typical profile is, women with serious social and family problems; one had been left by her husband, one had children who had been killed in accidents, one had been left by her family, one had well-established psychiatric problems."

Physician 2: "It's a patient who complains a lot, a patient who ends up having a lot of anxiety, depression... it's an ANNOYING patient."

The stigmatisation of women with CPP by health care providers is also related to the chronic nature of the disease, which entails difficulty in patient monitoring; because of the diagnostic and therapeutic limitations, the resolution rates for chronic conditions are low.

\subsection{Doctor-Patient Relationship}

Physician 4: "You have to listen to the patient's complaints, you cannot underestimate them, but you can't overestimate them, either, otherwise you'll be contributing to her attributing all her problems to that pelvic pain... You might contribute to her somatising the pain a bit, if that's the case, right?"

As previously described, we believe that the doctorpatient relationship problems in the context of CPP are intimately related to the stereotypical view that health professionals hold of those women. This creates a communication barrier between doctors and patients, the consequence being that the real needs of women with CPP are not met by the type of medical care provided by health professionals. Some of the statements clearly show that the physicians are insecure as to what criteria should define the threshold between believing and disbelieving in the discourse of women with CPP: "you can't underestimate [the complaints], but you can't overestimate them, either".

The mind-body dualism imposed by the biomedical model is in opposition to the multifaceted nature of pain. According to that fragmented view, the aetiology of the condition is exclusively physical or psychological, meaning that the pain is either "real" or "imaginary". In this sense, health professionals and patients grow increasingly apart in the setting of providing/obtaining treatment for CPP, the therapeutic relationship being often replaced by a relationship of distrust.

The benefits of a doctor-patient relationship that is based on an effective communication process include higher diagnostic accuracy, reduced number of lawsuits, increased treatment adherence, optimization of health resources, increased satisfaction, and better results in treating various conditions $[37,38]$. According to Morris [39], communication does not replace medical technology; rather, it aids in understanding the emotional and social factors that aggravate the condition. Neither extreme is ideal; there is a need to strike a balance between the two [39].

\subsection{Technical/Interventional Model}

Physician 4: "I think that, because the symptoms are extremely vague, sometimes clinical examination alone, sometimes the patient is unable to give you correct information, so you end up having to adopt a more invasive approach."

Physician 1: "The diagnosis of chronic pelvic pain is problematic, I think we still have a long way to go, I think certain mechanisms are missing, I mean, not that our facility lacks anything, but the fact is that CPP is a clinical diagnosis and is often secondary to a disease that requires an imaging test, blood tests, something that explains the pelvic pain."

The discourse of the participants reveals an over-reliance on the use of technology in the treatment of individuals, an approach that is consistent with the biomedical model of medical education and practice. The principal objective of the medical care provided to women with CPP has been to diagnose and treat the condition, other needs related to the health-illness continuum being put aside. That leads us to ask, "What are the real health care needs of women with CPP?" This excessive interventionism - characterised by the tyranny of ancillary tests; excessive fragmentation of patients into organs and functions; and inattention to emotional and psychosocial aspects-originates from the increasing technological sophistication of modern medicine and its sci ence-based approach [40]. 
Initially, this over-reliance on technology might be related to the need to visualise (i.e., biologically conceptualise) the pain. Subsequently, it is related to the need to establish an accurate and definitive diagnosis, which will in turn lead to the desired resolution of the symptom. However, the participants also attributed their overreliance on technology to their difficulty in understanding the complaints of women with CPP. According to the participants, because the complaints are subjective, invasive methods are needed in order to establish an accurate diagnosis.

Grace [41] and Price et al. [42] conducted qualitative studies investigating the perception that women with CPP have of the type of medical care received. The findings of those studies constitute evidence of the technical approach to health and show that health professionals reject and underestimate the complaints of those women, defining the symptoms on the basis of test results. In addition, women with CPP have reported that their anxieties are not allayed during medical appointments [41,42]. Some of the consequences of the over-reliance on technology in the health care setting include a strain on the doctor-patient relationship, the risk of iatrogenic complications, excessive specialization; institutionalization of medical care, and increased health care costs.

\subsection{Need for a Multidisciplinary Team}

Physician 6: "I think it should be a bit more integrated, especially in those patients in whom you can't find a specific cause. Oh, [integrated] with psychology, physiccal therapy."

Physician 6: "I believe that patients with chronic pelvic pain need a multidisciplinary approach."

Physician 5: "In my opinion, it is very difficult to treat women with chronic pelvic pain because there is a very strong psychological component; you have to address that."

The abovementioned statements show that the respondents recognise the importance of a multidisciplinary approach. However, their belief in the importance of a multidisciplinary approach is related to the difficulty that they have in managing aspects that are outside the realm of the technical and experimental. Therefore, the responsibility of addressing issues other than those of biological nature is handed over to other health professionals, which contributes to the fragmentation of health care.

According to Ferreira et al. [43], the treatment of chronic pain requires the involvement of an interdisciplinary team including physicians, nurses, physical therapists, and psychologists. The teams should provide information regarding the disease, as well as explore issues such as self-perception, attitude, and self-care in order to help those women develop better strategies to control the behaviours and experiences related to the disease [43].

\section{Discussion}

The limitations of the biomedical model become evident in the chronic pelvic pain care setting. The canons of biomedicine require that individuals be "pigeonholed" into pre-established disease categories often ignoring the multifaceted nature of the CPP. In recent decades, however, there has been an increasing concern over the training of future health professionals. The curriculum guidelines for undergraduate medical courses recommend the inclusion of ethical and humanistic dimensions that allow students to develop attitudes and values toward citizenship, in an attempt to combine technical excellence with humanistic traits.

In clinical practice, there has been a search for alternative methods of care (such as psychotherapy, acupuncture, and support groups) that permeate an ethical and humanistic model. Such methods allow us to achieve an integrated view of individuals, thereby making subjective expression, meanings, and worldviews central to the understanding of illness.

For some decades, the humanization of care has been on the agenda of certain entities supported by the World Health Organization. In recent years, the Brazilian National Ministry of Health has invested in improving hospital management and the medical care provided to the population, in an attempt to build a culture of humanistic care. The concept of humanization of care is based on the idea of a model that is focused on the possibility of communication and dialogue between users and health professionals. One of the greatest challenges in providing humanistic health care lies in reconciling quality health care-anchored in a well-established body of knowledge and based on the regularities of the health-illness continuum-with the subjective dimension and the sociocultural background of patients. However, in order to achieve a health care model that is based on such princeples, we need to go beyond the standard application of norms and rules of scientific medicine [40]. On the other hand, there are some important analogies to be made within the context of the CPP to emphasize the complexity of the condition. For example in the appropriate use of terms such as "disease and illness", where the latter term, which is more appropriate for the condition in question, is considered a complex interaction of psychological, social, medical or even the subject of the experience and self-attribution sometimes. This analogy leads us also to reflect about the concepts of nociception and pain. Studies have shown that brain regional changes, which occur only after input of the nociceptive CPP, play an important role in chronic pain. These changes, since it occurred, may contribute to a perception of pain continues even after the disappearance/removal of the initial 
nociceptive stimulus. Additionally, whether pain becomes chronic depends on the interaction of various factors, namely the persistence of the peripheral pain generator, the antinociceptive capacity, and (maladaptive) neuroplasticity of the pain system [44]. Accordingly, the problem involving the CPP must not be limited of the biomedical model or quality of care.

\section{Final Consideration}

In the present study, we investigated the perception that health professionals have of the problems related to the treatment of chronic pelvic pain. Although the present study is by no means definitive, we believe that it provides the basis for further discussion of the model on which medical education and practice are currently based, as well as of the possibility of adjusting or even restructuring that model.

Through these considerations we propose that the theme be included in the curricula of undergraduate medical schools as soon as possible; that our findings be directly applied to clinical practice; and that chronic pelvic pain treatment protocols emphasizing the biopsychosocial aspects of the disease be established. Qualitative studies of chronic pelvic pain have contributed to important changes in our facility, including changes in the physical structure in order to improve the quality of the medical care provided to patients; adoption of a more humane approach to patients; interaction among the members of the multidisciplinary health care team, psychologists actively participating in the medical care provided; and association between teaching and research, which allows the discussion of research topics that can aid in gaining a deeper understanding of chronic pelvic pain [22].

\section{REFERENCES}

[1] M. J. O. Carvalho, "Dor: Um Estudo Multidisciplinar," São Paulo, 1999.

[2] J. J. Bonica, "The Management of Pain of Cancer," Michigan State Medical Society, Vol. 52, 1953, pp. 284290.

[3] IASP, "Pain Terms: A List with Definitions and Notes on Usage,” IASP Subcommittee on Taxonomy, Pain, 1979, pp. 6-249.

[4] F. A. E. F. Sousa, "Dor: o Quinto Sinal Vital," Rev Latino-am Enfermagem, Vol. 10, No. 3, 2002, pp. 446-447. doi:10.1590/S0104-11692002000300020

[5] A. P. M. S. Romão, R. Gorayeb, G. S. Romão, O. Polineto, F. J. C. Reis, J. C. R. Silva and A. A. Nogueira, "High Levels of Anxiety and Depression Have a Negative Effect on Quality of Life of Women with Chronic Pelvic Pain,” International Journal of Clinical Practice, Vol. 63, No. 5, 2009, pp. 707-711. doi:10.1111/j.1742-1241.2009.02034.X
[6] F. M. Howard, "Chronic Pelvic Pain,” Obstetrics \& Gynecology, Vol. 101, No. 3, 2003, pp. 594-611. doi:10.1016/S0029-7844(02)02723-0

[7] K. Zondervan and D. H. Barlow, "Epidemiology of Chronic Pelvic Pain. Baillieres Best," Practice \& Research Clinical Obstetrics \& Gynaecology, Vol. 14, 2000, pp. 403-414.

[8] ACOG, ACOG Practice Bulletin No. 51, "Chronic Pelvic Pain,” Obstetrics \& Gynecology, Vol. 103, No. 3, 2004, pp. 589-605.

[9] K. T. Zondervan, P. L. Yudkin, M. P. Vessey, M. G. Dawes, D. H. Barlow and S. H. Kennedy, "Patterns of Diagnosis and Referral in Women Consulting for Chronic Pelvic Pain in UK Primary Care,” British Journal of Obstetrics and Gynaecology, Vol. 106, No. 11, 1999, pp. 1156-1161. doi:10.1111/j.1471-0528.1999.tb08141.x

[10] P. Latthe, M. Latthe, L. Say, M. Gulmezoglo and K. S. Khan, "WHO Systematic Review of Prevalence of Chronic Pelvic Pain: A Neglected Reproductive Health Morbidity,” BMC Public Health, Vol. 6, No. 177, 2006.

[11] G. P. Silva, A. L. Nascimento, D. Michelazzo, F. F. Alves Jr., M. G. Rocha, J. C. Silva, et al., "High Prevalence of Chronic Pelvic Pain in Women in Ribeirao Preto, Brazil and Direct Association with Abdominal Surgery,” Clinics, Vol. 66, No. 8, 2011, pp. 1307-1312.

[12] S. D. Mathias, M. Kuppermann, R. F. Liberman, R. C Lipschut and J. F. Steege, "Chronic Pelvic Pain: Prevalence, Health-Related Quality of Life, and Economic Correlates," Obstetrics \& Gynecology, Vol. 87, No. 3, 1996, pp. 321-327. doi:10.1016/0029-7844(95)00458-0

[13] C. A. Winkel, "Modeling of Medical and Surgical Treatment Costs of Chronic Pelvic Pain: New Paradigms for Making Clinical Decisions," American Journal of Managed Care, Vol. 5, 1999, pp. 276-290.

[14] J. D. Parker, M. Leondires, N. Sinaii, A. Premkumar, L. K. Nieman and P. Stratton, "Persistence of Dysmenorrhea and Nonmenstrual Pain after Optimal Endometriosis Surgery May Indicate Adenomyosis,” Fertility and Sterility, Vol. 86, No. 3, 2006, pp. 711-715. doi:10.1016/j.fertnstert.2006.01.030

[15] L. Cox, S. Ayers, K. Nala and J. Penny, "Chronic Pelvic Pain and Quality of Life after Laparoscopy,” European Journal of Obstetrics \& Gynecology and Reproductive Biology, Vol. 132, 2007, pp. 214-219. doi:10.1016/j.ejogrb.2006.04.020

[16] F. M. Howard, "The Role of Laparoscopy in Chronic Pelvic Pain: Promise and Pitfalls,” Obstetrical \& Gynecological Survey, Vol. 48, 1993, pp. 357-387. doi:10.1097/00006254-199306000-00001

[17] M. S. Broder, D. E. Kanouse, B. S. Mittman and S. J. Bernstein, "The Appropriateness of Recommendations for Hysterectomy,” Obstetrics \& Gynecology, Vol. 95, 2000, pp. 199-205. doi:10.1016/S0029-7844(99)00519-0

[18] J. C. Gambone, B. S. Mittman, M. G. Munro, A. R. Scialli and C. A. Winkel, "Consensus Statement for the Management of Chronic Pelvic Pain and Endometriosis: Proceedings of an Expert-Panel Consensus Process," Fertility and Sterility, Vol. 78, 2002, pp. 961-972. 
doi:10.1016/S0015-0282(02)04216-4

[19] Y. Cheong and S. R. William, "Chronic Pelvic Pain: Aetiology and Therapy,” Best Practice \& Research Clinical Obstetrics \& Gynaecology, Vol. 20, 2006, pp. 695-711. doi:10.1016/j.bpobgyn.2006.04.004

[20] S. A. Selfe, M. Van Vugt and R. W. Stones, "Chronic Gynaecological Pain: An Exploration of Medical Attitudes,” Pain, Vol. 77, 1998, pp. 215-225. doi:10.1016/S0304-3959(98)00104-3

[21] B. Barzansky, "Abraham Flexner and the Era of Medical Education Reform,” Academic Medicine, Vol. 85, No. 9, 2010, pp. 19-25. doi:10.1097/ACM.0b013e3181f12bd1

[22] P. P. Souza, R. Salata, J. C. Rosa-e-Silva, F. Candidodos-Reis, A. A. Nogueira and O. B. Poli-Neto, "Qualitative Research as the Basis for a Biopsychosocial Approach to Women with Chronic Pelvic Pain,” Journal of Psychosomatic Obstetrics and Gynecology, Vol. 32, No. 4, 2011, pp. 165-172. doi:10.3109/0167482X.2011.607523

[23] R. Ruiz-Moral, E. P. Rodriguez, L. A. Perula de Torres and J. de la Torre, "Physician-Patient Communication: A Study on the Observed Behaviours of Specialty Physicians and the Ways Their Patients Perceive Them," $\mathrm{Pa}$ tient Education and Counseling, Vol. 64, No. 1-3, 2006, pp. 242-248. doi:10.1016/j.pec.2006.02.010

[24] R. W. Stones, W. T. Lawrence and S. A. Selfe, "Lasting Impressions: Influence of the Initial Hospital Consultation for Chronic Pelvic Pain on Dimensions of Patient Satisfaction at Follow-Up," Journal of Psychosomatic Research, Vol. 60, No. 2, 2006, pp. 163-167. doi:10.1016/j.jpsychores.2005.06.077

[25] S. R. Hahn, K. Kroenke, R. L. Spitzer, D. Brody, J. B. Williams, M. Linzer, et al., "The Difficult Patient: Prevalence, Psychopathology, and Functional Impairment,” Journal of General Internal Medicine, Vol. 11, No. 1, 1996, pp. 1-8. doi:10.1007/BF02603477

[26] E. A. Walker, W. J. Katon, D. Keegan, G. Gardner and M. Sullivan, "Predictors of Physician Frustration in the Care of Patients with Rheumatological Complaints,” General Hospital Psychiatry, Vol. 19, 1997, pp. 315-323. doi:10.1016/S0163-8343(97)00042-X

[27] D. J. Cegala, T. Marinelli and D. Post, "The Effects of Patient Communication Skills Training on Compliance," Archives of Family Medicine, Vol. 9, 2000, pp. 57-64. doi:10.1001/archfami.9.1.57

[28] A. Charpentier, M. Goudemand and P. Thomas, "Therapeutic Alliance, a Stake in Schizophrenia,” Encephale, Vol. 35, 2009, pp. 80-89. doi:10.1016/j.encep.2007.12.009

[29] E. H. Lin, W. Katon, M. Von Korff, T. Bush, P. Lipscomb, J. Russo and E. Wagner, "Frustrating Patients: Physician and Patient Perspectives among Distressed High Users of Medical Services,” Journal of General Internal Medicine, Vol. 6, 1991, pp. 241-246. doi:10.1007/BF02598969

[30] J. L. Jackson and K. Kroenke, "Difficult Patient Encounters in the Ambulatory Clinic: Clinical Predictors and Outcomes," Archives of Internal Medicine, Vol. 159,
1999, pp. 1069-1075. doi:10.1001/archinte.159.10.1069

[31] L. Bardin, “Análise de Conteúdo,” Press Universitaires de France, Lisboa, 1977.

[32] M. C. S. Minayo, “A Inclusão da Violência na Agenda da Saúde: Trajetória Histórica,” Saúde \& Ciências Coletiva, Vol. 11, 2007, pp. 1259-1267. doi:10.1590/S1413-81232006000500015

[33] M. A. Lima and L. A. Trad, "The Medical Perspective towards Chronic Pain: Biomedical Model and Clinical Practice,” Cadernos de Saúde Pública, Vol. 23, 2007, pp. 2672-2680. doi:10.1590/S0102-311X2007001100015

[34] V. M. Grace, "Problems of Communication, Diagnosis, and Treatment Experienced by Women Using the New Zealand Health Services for Chronic Pelvic Pain: A Quantitative Analysis,” Health Care for Women International, Vol. 16, 1995, pp. 521-535. doi:10.1080/07399339509516207

[35] P. Salmon, "Patients Who Present Physical Symptoms in the Absence of Physical Pathology: A Challenge to Existing Models of Doctor-Patient Interaction," Patient Education and Counseling, Vol. 39, 2000, pp. 105-113. doi:10.1016/S0738-3991(99)00095-6

[36] C. D. Ponte and J. Johnson-Tribino, “Attitudes and Knowledge about Pain: An Assessment of West Virginia Family Physicians," Family Medicine Journal, Vol. 37, 2005, pp. 477-480.

[37] M. Stewart, J. Brown, S. Donner, I. R. McWhinney, J. Oates, W. W. Weston and J. Jordan, "The Impact of Patient-Centered Care on Outcomes,” Journal of Family Practice, Vol. 49, 2000, pp. 796-804.

[38] M. M. Alamo, R. R. Moral and L. A. Perula de Torres, "Evaluation of a Patient-Centred Approach in Generalized Musculoskeletal Chronic Pain/Fibromyalgia Patients in Primary Care," Patient Education and Counseling, Vol. 48, 2002, pp. 23-31. doi:10.1016/S0738-3991(02)00095-2

[39] D. B. Morris, "Illness and Culture in the Postmodern Age,” The University of California Press, London, 1998. doi:10.1525/california/9780520208698.001.0001

[40] S. F. Deslandes, "Humanização dos Cuidados em Saúde: Conceitos, Dilemas e Práticas,” Editora Fiocruz, Rio de Janeiro, 2006.

[41] V. M. Grace, "Problems Women Patients Experience in the Medical Encounter for Chronic Pelvic Pain: A New Zealand Study," Health Care for Women International, Vol. 16, 1995, pp. 509-519. doi:10.1080/07399339509516206

[42] J. Price, G. Farmer, J. Harri, T. Hope, S. Kennedy and R. Mayou, "Attitudes of Women with Chronic Pelvic Pain to the Gynaecological Consultation: A Qualitative Study,” BJOG, Vol. 113, 2006, pp. 446-452. doi:10.1111/j.1471-0528.2006.00862.x

[43] K. A. S. L. Ferreira, S. R. D. T. Siqueira and M. J. Teixeira, "Characteristics of Pain, Demographic and Treatment of Patients Attending a Multidisciplinary Pain Center," Caderno de Saúde Coletiva, Vol. 16, 2008, pp. 449-470.

[44] A. S. Sawsan, E. H. Richard, N. Vitaly, K. Jieun, N. Gina, K. Anson, W. David, J. C. Daniel and S. W. Tobias, 
"Changes in Regional Gray Matter Volume in Women with Chronic Pelvic Pain: A Voxel-Based Morphometry
Study,” Pain, Vol. 153, No. 5, 2012, pp. 1006-1014. doi:10.1016/j.pain.2012.01.032 